COMMENT

DOI: 10.1057/s41599-018-0194-5

\title{
Social norms and farm animal protection
}

Nicolas Delon ${ }^{1}$

\begin{abstract}
Social change is slow and difficult. Social change for animals is formidably slow and difficult. Advocates and scholars alike have long tried to change attitudes and convince the public that eating animals is wrong. The topic of norms and social change for animals has been neglected, which explains in part the relative failure of the animal protection movement to secure robust support reflected in social and legal norms. Moreover, animal ethics has suffered from a disproportionate focus on individual attitudes and behavior at the expense of collective behavior, social change, and empirical psychology. If what we want to change is behavior on a large scale, norms are important tools. This article reviews an account of social norms that provides insights into the possibility and limitations of social change for animals, approaching animal protection as a problem of reverse social engineering. It highlights avenues for future work from this neglected perspective.
\end{abstract}

\footnotetext{
${ }^{1}$ New College of Florida, Philosophy \& Environmental Studies, Sarasota, FL, USA. Correspondence and requests for materials should be addressed to N.D. (email: ndelon@ncf.edu)
} 


\section{Introduction}

ocial change is slow and difficult. Social change for animals is formidably slow and difficult, arguably slower than the increasing global trends in meat consumption and intensification of farming practices. ${ }^{1}$ Animal advocates and scholars alike have long tried to change attitudes and convince the public that eating animals is wrong. This article sets aside this question, ${ }^{2}$ taking up instead the question of how to foster change given the reasonably uncontroversial assumption that we have strong reasons, moral and otherwise, not to cause unnecessary animal suffering and other nefarious (environmental, public health ${ }^{3}$, and social) consequences of factory farming. Sentient animals, who are capable of pleasant and unpleasant experiences, deserve at least some moral consideration that is incompatible with the treatment to which most currently farmed animals are subjected. Readers should note that they can adjust the assumption to whatever baseline of decency they believe is required. Plausibly, some social change is required anyway. If readers believe no change is required, then they may be among the targets of this article. This exploratory article seeks to clarify the problem of animal welfare under a new light.

Why focus on norms? First, it is a neglected topic in the literature on animal rights and animal welfare. This explains in part the relative failure of the animal protection movement to secure robust support reflected in social and legal norms. A related reason is that animal ethics has hitherto suffered from a disproportionate focus on individual attitudes and behavior at the expense of social change and empirical psychology. Recently, however, philosophers have come to terms with this failure and begun to approach animal welfare as a collective action problem (Budolfson, 2015a; Nefsky, 2018) as well as one of psychology (Caviola et al., 2018; Kasperbauer, 2018). This recent literature motivates the present hypothesis, that unless we address animal welfare as a problem of social change, changing individual attitudes toward animals has little chance of effectively helping animals. The harms caused by factory farming, and animal agriculture more generally, are, like many environmental issues, a large coordination problem. Hundreds of thousands may have changed their views and diet after reading Peter Singer's Animal Liberation, taking an Animal Ethics class, reading a go veg! leaflet or watching a gruesome video. What impact their individual changes had on animal suffering is a distinct question (hint: little). Attitudinal change in a context of deeply entrenched anthropocentrism has rather low tractability. Moreover, individual consumers in large-scale collective action problems are largely inefficacious because everyone has at best a minuscule probability of affecting the outcome. Here is another way to capture the problem: even if it's wrong to cause unnecessary suffering to animals and animal agriculture is causing them disproportionate amounts of unnecessary suffering, it does not necessarily follow that it's wrong (for you) to eat animals.

The question is thus not how we can change attitudes but how norms affect behavior and how they can be altered. If behavior is to be changed on a large scale, norms are important tools. But we need to look at other cases of shifts in social norms-e.g., smoking, same-sex marriage, among others-to illustrate their power, the mechanisms that best explain them, and ask if we can expect similar mechanisms at play in the animal case. Such detailed exploration is beyond the scope of this comment. Its goal is to describe the problem and suggest future directions for work on the tools of social change for animals. The problem is one of reverse social engineering. We look at how norms have produced change in the past and how the norms themselves were produced. This is a stepping stone into such engineering.

Section 1 describes the current treatment of most domestic animals in the U.S. as a problem of normalization. Section
2 specifies what is meant by social norms, and how recent accounts of social norms shed light on the mechanisms of social change. Section 3 highlights the relevance of these theoretical insights to animal welfare and hints at potential obstacles.

\section{The normalization of customary practices}

Only a tiny fraction of the animals with whom we interact are not raised for food. Writing in 2004, David Wolfson and Marian Sullivan note that, as of 2001, approximately 9.5 billion animals were slaughtered annually in food production in the United States, compared to 218 million killed by hunters and trappers and in animal shelters, biomedical research, product testing, dissection, and fur farms, combined. "From a statistician's point of view, since farmed animals represent 98 percent of all animals (even including companion animals and animals in zoos and circuses) with whom humans interact in the United States, all animals are farmed animals; the number that are not is statistically insignificant." (Wolfson and Sullivan, 2004, p. 206).

This means that $98 \%$ of the animals Americans interact with have nearly no legal protection. ${ }^{4}$ The federal Animal Welfare Act, which sets basic standards for the care of animals, simply exempts farmed animals. No other federal law applies to raising animals. Besides the 28-hour transport law, the Humane Slaughter Act is the main piece of federal legislation protecting farmed animals and requires that livestock slaughter "be carried out only by humane methods" to prevent "needless suffering." But regulations promulgated pursuant to the statute exempt poultry. That is, over 95 percent of all farmed animals (approximately 8.5 billion slaughtered per year) have no federal legal protection from inhumane slaughter. And for those covered, no fines are applicable for violation of the statute and significant penalties are never imposed. (Wolfson and Sullivan, 2004, p. 207-208)

Are state legislations more adequate? State anticruelty statutes are criminal statutes covering all animals. For this reason, they are worded "in very broad and largely undefined terms, and do not specifically require affirmative acts, such as adequate exercise, space, light, ventilation, and clean living conditions." (p. 209) The farming industry is not like other industries, typically governed by regulatory schemes promulgated and enforced by agencies. Anticruelty statutes do not provide for specific welfare regulations, regulatory enforcement of welfare standards, inspections, or responsibility to any state or federal administrative agency. Their enforcement, like other criminal statutes, is left primarily to the police and prosecutors, for whom farming practices usually don't have priority. Yet, even though it faces nearly zero risk of prosecution, the industry has challenged these statutes. Since the 1990s, the majority of states with such statutes have persuaded state legislatures to amend them to exempt all (or in rare cases some) "accepted," "common," "customary," or "normal" farming practices. There is no statutory definition of customary practices, but they include such things as intensive confinement (gestation and farrowing crates, veal crates, battery cages), non-anesthetized debeaking, dehorning, and castration, and repeated impregnation. As a result, whatever the industry does determines what is accepted, hence exempted. Customary farming practices are beyond the reach of U.S. courts even while they would be considered cruel, for instance, by current European standards.

To understand the impact of these legal exemptions, it is worth delving into the concept of normality. Folk conceptions can illuminate an important connection between social norms and normality. Social norms both generate and rely on beliefs that a behavior is normal. Adam Bear and Joshua Knobe conducted a series of experiments examining the folk understanding of normality. They found that people tend to combine a sense of what is 
typical with a sense of what is ideal (Bear and Knobe, 2017a). Normal is a statistical-evaluative complex. One of their examples is, "What is the normal / average / ideal number of hours of TV for a person to watch in a day?" Participants answered differently for each version: "normal" (about $3 \mathrm{~h}$ ), "average" (about 4), and "ideal" (about 2.5). This suggests that judgments of normality deviate from the average toward an evaluative standard. Other examples follow this pattern: the normal grandmother, the normal salad, the normal number of students to be bullied in a middle school. These findings illustrate an intriguing feature of our minds-that in our ordinary thinking, we often cannot separate the average from the ideal, the descriptive from the prescriptive. Moral norms (or the ideal) impact the acquisition of normality; conversely, normality (perceived social norms) impacts the acquisition of moral norms.

"The consequences can be serious," Bear and Knobe (2017b) note. For example, as "President Trump continues to do things that once would have been regarded as outlandish, these actions are not simply coming to be regarded as more typical; they are coming to be seen as more normal. As a result, they will come to be seen as less bad and hence less worthy of outrage." These findings help to shed light on the "normalization" of customary farming practices. The flipside is that this should be true of "any other controversial institution or practice that becomes more widespread", including same-sex marriage or gender reassignment surgery. Also, despite this ingrained tendency, we are "capable of distinguishing carefully between what is typical and what is good." Nonetheless, this tendency can override individuals' reasoning capacities, and judgments of normality are central to various aspects of cognition. The "normalization trap" can therefore be a genuine source of concern as well as positive change (altering perceptions of acceptability-the salience of the ideal-can shift the average by decreasing the likelihood of conformity).

There is evidence of the power of normalization in the case of meat-eating behavior. Jared Piazza et al. (2015) drew on psychologist Melanie Joy's "Three Ns" theory of "carnism"-i.e., that beliefs that eating meat is necessary, natural, and normal are the main justifications that people give for eating animals (Joy, 2009). Piazza and colleagues recruited omnivores in the U.S. and asked them "Why is it OK to eat meat?" After categorizing their responses, they found that people actually offered Joy's three Ns but also frequently a fourth $\mathrm{N}$-eating meat is nice (i.e., pleasurable, tasty, etc.). ${ }^{5}$ In studies $3-5$, authors also showed that individuals who endorsed the $4 \mathrm{Ns}$ tend not to be motivated by ethical concerns when making food choices, are less proud of their animal-product decisions, consume meat and animal products more frequently, and are highly committed to it. The $4 \mathrm{Ns}$ can have a strong self-serving, rationalizing power for omnivores. While normality appears to be just a subset of the main justifications for eating meat, social norms are tied to all four justifications, in the sense that they involve both empirical and normative expectations (about what others do and what they consider acceptable). Indeed, necessary, natural, normal, and nice all carry a blend of descriptive and prescriptive elements.

With customary practices and a new account of normality in the background, let us now briefly introduce an account of social norms. Inherent in the account are the causes and consequences of social norms, hence of norm change.

\section{What are social norms?}

Norms come in various types and shapes. There are norms of etiquette, conventions, rules of games, political norms, and religious, social, and moral norms. There are descriptive and prescriptive norms. While the former capture actual patterns of behavior, the latter are meant to guide behavior. Of course, successful prescriptive norms are also descriptive: they generate general compliance, which in turns reinforces them.

There are also various theories of norms. For present purposes, norms are understood as patterns of behavior and attitudes. They do not merely reflect behavioral regularities but also involve characteristic attitudes that partly explain their presence (i.e., emergence, stabilization, and reinforcement). Such attitudes may contribute to justifying norms, but they may as well reflect perceived justifications of the norms. The relation between explanation and justification is further complicated by the existence of different types of norms. Reasons accepted in the legal domain may be questioned morally; legal reasons may also fail to reflect socially endorsed reasons. So, we can conceive of norms as complexes of behavior and attitudes, and as having effects on behavior, rather than constituted by behavioral patterns, following philosopher Philip Pettit (2002) and a number of legal scholars and social scientists (e.g., Bicchieri, 2017; McAdams, 2000a, b, 2015; Sunstein, 1996). For instance, Pettit's attitudebased theory "starts with an explanation of why the behavior attracts approval and then invokes the existence of that pattern to explain the appearance of a regularity in that behavior." (Pettit, 2002, p. 280) Since reputation is a good, it can reward (punish) perceived good (bad) behavior. Both agents and their judges can enact such reputational flows unintentionally. This helps to explain the spontaneous emergence and stabilization of norms in societies. On Pettit's account, a regularity counts as a norm when (i) it is generally displayed, (ii) those subject to the norm generally approve (disapprove) of others' conforming (deviating), and (iii) the pattern of approval and disapproval is part of the explanation of the general conformity with the regularity (Pettit, 2002, p. 279).

Decades of social science have demonstrated that personal attitudes are at best very weakly predictive of behavior. Research shows that "the main variable affecting behavior is not what one personally likes or thinks he should do, but rather one's beliefs about what 'society' (i.e., most other people, people who matter to us, and the life) approves of" (Bicchieri, 2017, p. 10). In Bicchieri's account of social norms, the key mental states are the beliefs and conditional preferences of social actors. Normative social expectations express beliefs about other people's beliefs about the social acceptability of certain behaviors (p. 12). The importance of social expectations underlines that of reference networks, "the range of people whom we care about when making particular decisions", "against which expectations are set" (p. 14). This could include friends and family, a village, a religious group, people in one's home country, and so forth. Social norms will change within the reference network.

Bicchieri further distinguishes descriptive and social norms. Descriptive norms are patterns of behavior such that individuals prefer to conform to them on condition that they believe that most people in their reference network conform to them (empirical expectation). (p. 19) Social norms are rules of behavior such that individuals prefer to conform to them on condition that they believe that (a) most people in their reference network conform to them (empirical expectation), and (b) that most people in their reference network believe they ought to conform to them (normative expectation). (p. 35) Expectations affect behavior because the preference for complying is conditional on one's social expectations. Social norms rely on empirical expectations (about what others do), as well as normative expectations (about what others believe one ought to do). Deviating from conventions or customs is inherently costly (driving in the wrong lane, breaking norms of grammar): they are such that it is better to follow them. Social norms are not self-enforcing in this way: sanctions and rewards like appreciation, trust, respect, social identity, and the benefits of coordination can elicit compliance. 
In the next section, let us examine how this account of social norms can explain the persistence of our dietary practices, and what room it leaves for social change for animals.

\section{Social norms and animals}

People's dietary habits are reinforced by both descriptive and prescriptive norms (following the "4Ns"). Not all dietary habits are mere customs -patterns of behavior consisting of a selfreproducing collection of similar actions, "such that individuals (unconditionally) prefer to conform to it because it meets their needs." (Bicchieri 2017, p. 15) Customs can act as "drags on social change" since, no matter what others do or believe, (perceived) need provides sufficient motivation. Even though eating meat on a regular basis is not a need for most people, it is often perceived as one (i.e., "necessary" in the $4 \mathrm{Ns}$ ). But, as noted, dietary habits also involve norms further entrenching meat-eating behavior (Joy, 2009). We can capture the persistence of eating meat as a social norm, sustained by empirical and normative expectations also expressed by legal and market norms. It is more than a mere custom because the perception of need is not sufficient to sustain the practice. Only in the context of other beliefs and values does this perceived need acquires normative force. Together, these normative features of omnivore practices constitute a drag on social change for animals.

Furthermore, change is hindered by the phenomenon of pluralistic ignorance, whereby people infer that others hold attitudes consistent with their observed behavior. Belief in descriptive norms leads to the (self-serving) belief that the observed behavior is normative and the object of mutual approval, regardless of actual attitudes (Bicchieri, 2017, p. 42-47; Prentice and Miller, 1996). For instance in BRIC countries, people may underestimate the level of support among their co-citizens for animal welfare. Anderson and Tyler (2018, p. 8) note that

many people may hold the same attitude while simultaneously believing everyone else holds a different attitude, because no one talks about their privately held beliefs ... People tend to avoid talking about the welfare of farmed animals, so many individuals may privately hold more proanimal beliefs than is apparent from their behavior. This information is useful to advocates ... There may be room to increase public support for animal advocacy in [BRIC] countries simply by making people aware that many others also think animal welfare is important.

Pluralistic ignorance may also partly explain the so-called "meat paradox", i.e., that most people eat meat yet many of them experience moral discomfort when they do (Bastian and Loughnan, 2016).

Dietary practices present an astute challenge because they are tied to a variety of domains - taste, tradition, religion, and culture - that involve emotions, rituals, commitments, and values that eschew reasoning and can be central to identities. As Bicchieri notes, "If the issue being discussed is emotionally loaded, as is often the case when discussing core values and especially in cases of moral dumbfounding ... arguing about the issue may prompt the listeners to stonewall the argument." (2017, p. 159) This suggests that deliberation about eating animals should be sensitive to cultural specificities (see Bilz and Nadler, 2014).

Social norms do not operate in a vacuum. They are part of complex webs of factual and normative beliefs. Empirical investigation could reveal that some moral commitments are more central to people's identities than various ideological, religious, and cultural commitments. And information about the harms caused by farming as well as deliberation about beliefs and values could lead to revision. For instance, harm appears to be a key anchor across most cultures. Relying on extensive anthropological literature, Shaun Nichols (2004) argues that harm-norms have been pervasive, albeit with different forms and content, across nearly all human cultures. To the extent that some harm-norms are central to societies, new norms framed in terms of harm have a better chance of spreading and being internalized. Nichols (chapters 6-7) also offers a fascinating account of the evolution of such norms, including regarding cruelty to animals over the last few centuries.

Harm is one basis of moral and social norms, but there are others. According to Jonathan Haidt and colleagues, human morality is determined by six moral foundations: care vs. harm, fairness vs. cheating, loyalty vs. betrayal, sanctity vs. degradation, authority vs. subversion, and liberty vs. oppression, identified from decades of surveys and experiments (Haidt and Graham, 2007). Although these are universal foundations, some human groups express some more than others. In American society, Haidt and his colleagues have argued that political liberals prioritize fairness and caring, while conservatives also place importance on loyalty, purity and other values tied to dominance hierarchies (Graham et al., 2009). Graham et al. (2011) found evidence of this asymmetry in twelve different regions of the world. Drawing on this research, Kasperbauer (2018, p. 153-158) infers that harm to animals is not a priority concern for certain social categories. He further suggests how to tactically motivate support for reforms across political lines: "instead of framing duties to animals in terms of harm (Animals must not be made to suffer) or fairness (All sentient beings deserve equal treatment), duties could be framed in terms of loyalty (Americans show compassion toward animals). And within specific domains of animal use, improved welfare standards could perhaps be framed in terms of purity (e.g., Cruel treatment of livestock makes our food unsafe to eat)." (p. 190)

So how does change happen? Bicchieri reviews several tools of social change: law, media campaigns (including popular culture and trendsetters), economic incentives, and deliberation, which often perform the double function of changing perceptions of certain practices and their expectations about whether other people will still follow and/or endorse them. These tools have four prerequisites. First, there must be shared reasons for the change. A variety of factors can make such reasons emerge or crystallizetechnology, factual information, shifts in values or in social expectations. While the power of ethics to effect change is limited, one may hope that arguments in animal ethics can contribute to those shared reasons, as has, famously, Peter Singer's Animal Liberation. Second, we must be confident that others would act similarly, otherwise deviation might have negative consequences (exclusion from social benefits, bad reputation, ostracism...). Third, coordination is often necessary. With descriptive norms, this is easily achieved by communication within the reference network, but sometimes it is "risky to be a "first mover"" (Bicchieri, 2017, p. 109), unless one is a trendsetter. With meat, we are vulnerable to a typical collective action problem. It's individually more convenient for most people not to make the shift on their own, regardless of the expected benefits of collective change. The fourth prerequisite follows from the need for coordination: collective change of expectations. For instance, with water consumption, public reports that consumption is steadily diminishing can help coordinate actions and expectations by raising confidence that one's personal water-preserving efforts will not be in vain. (p. 110)

In sum, changing norms in large-scale collective action problems is itself a coordination problem. Information campaigns, public declarations, and common pledges can help to motivate and synchronize those tempted to deviate and establish new 
norms (Bicchieri and Mercier, 2014). For now, animal welfare may not meet either of these prerequisites.

Future work should look in more detail at when these tools, when the prerequisites were met, effectively produced change, and if the same conditions can be met in the animal case. Case studies include the abolitionist and civil rights movement, the marriage equality movement, and the regulation of smoking, as well as different tactics currently used by the animal rights movement (courts, direct action, grassroots organizing, information campaigns, and legislative lobbying). ${ }^{7}$ Besides, critical attention should be paid to the use of regulatory cost-benefit analysis internalizing "moral commitments," including willingness-to-pay for animal welfare (see Posner and Sunstein, 2017; but see Kuenzler and Kysar, 2014), nudges and marketbased strategies, the role of shame (Jacquet, 2015; but see Nussbaum, 2004) and other potential enforcers of social norms like trendsetters (e.g. vegan celebrities), judicial activism, and state ballot initiatives (Bollard, 2017). Finally, it will be important to separate cases based primarily on self-interest from those based on other-regarding considerations. ${ }^{8}$ For, even though smoking falls into the former category, its moralization owed a lot to the perception that it could harm others (Bilz and Nadler, 2014). A similar path might be promising for animal welfare. Of course, social change is only a part of broader societal change including political, economic and technological change. There is all reason to expect that, say, increased bipartisan support and the rise of synthetic animal products could set a new stage for a shift in social norms, and vice versa. Yet consider same-sex marriage. Three conditions of the success of the marriage equality movement may, for now, be missing for animals: (i) the presence of many LGBT people in many families across the political spectrum; (2) the existence of norm entrepreneurs in prominent socio-economic positions, who may or often may not have disclosed their homosexuality; (3) the fact that marriage equality didn't require that people change their way of life. ${ }^{9}$ Farm animals obviously fail the first two conditions. Animal advocates, however, can fill the spot. And technological change (e.g., cellular agriculture) may at some point make it convenient for many people to abstain from animal products without significantly altering their way of life (Shapiro, 2018). ${ }^{10}$ These changes can, in turn, alter both normative and empirical expectations to foster norm change.

This article has described the ways in which animal protection can be fruitfully approached from the perspective of norms. Eating meat is normal. This means that the problem cannot simply be addressed as a problem of attitudinal change. If we can reverse engineer both the current state of affairs regarding animals and relevantly similar examples of social change, then we might uncover potent social tools.

Received: 15 August 2018 Accepted: 31 October 2018

Published online: 20 November 2018

\section{Notes}

1 This is true in no small part due to upward trends in BRIC countries (Brazil, Russia, India, China) (Anderson and Tyler, 2018). Importantly, though, welfare reforms could garner significant support in some BRIC countries (Ibid.). There is some anecdotal evidence that vegetarianism and veganism have increased in some developed countries like the U.K., but the evidence is not conclusive (the numbers remain very low and steady in the U.S., for instance).

2 A 2015 Gallup poll (http://news.gallup.com/poll/183275/say-animals-rights-people. aspx) found that $32 \%$ of Americans said they believe "animals deserve the exact same rights as people to be free from harm and exploitation" (up from $25 \%$ in 2008), $62 \%$ say they deserve some protection but can still be used for the benefit of humans, yet only $26 \%$ are "very concerned" about the current treatment of US farm animals. One possible explanation is ignorance of standard practices. For example, $60 \%$ of Americans thought that "the majority of pigs raised for pork in the United State have access to the outdoors at least some portion of each day." (Cummins et al., 2015). In the meantime, while numbers have been up, only between 2 and $6 \%$ of Americans self-identify as vegetarian or vegan, with many of them actually reporting they not infrequently eat meat (https://animalcharityevaluators.org/blog/is-thepercentage-of-vegetarians-and-vegans-in-the-u-s-increasing/).

3 This includes contribution to cardiovascular diseases, diabetes, and respiratory illnesses in humans, and antibiotic resistance among farm animals.

4 Discussion in this section is restricted to the U.S. context. Where, like in the European Union, animal welfare regulations are more stringent, the problem of farm animal protection is still one of social norms.

5 The $4 \mathrm{~N}$ classification captures the vast majority (83-91\%) of offered justifications. "Necessary" was the most widespread, but "Natural" and "Nice" were the most highly endorsed.

6 For a new norm to emerge, normative expectations have to change first, and empirical expectations follow. To abandon a norm, it is the other way around. (Bicchieri 2017, p. 111)

7 For skeptical takes on the power of courts to effect change, see, e.g., Bilz and Nadler (2014) and Rosenberg (2008).

8 Contrary to animal advocacy, past social movements have involved members of human society, or members of the workforce who have (strictly) economic or productive value (Leiter, 2013). Negative attitudes or moral indifference toward members of other species, combined with self-interest, constitute a major obstacle to change which future work needs to grapple with (Caviola et al., 2018)

9 Thanks to Martha Nussbaum for these insights.

10 One may expect some resistance, based in particular on the "4Ns", if people see cultured meat as unnatural. Thanks to an anonymous reviewer for making this point.

\section{References}

Anderson J, Tyler L (2018) Attitudes towards farm animals in the BRIC countries. Faunalytics. 1p62y3me6en712a5yp0xm1gq1zf3nj9m3mq. Accessed 16 Oct 2018

Bastian B, Loughnan S (2016) Resolving the meat-paradox: a motivational account of morally troublesome behavior and its maintenance. Personal Social Psychol Rev 21(3):278-299

Bear A, Knobe J (2017a) Normality: part descriptive, part prescriptive. Cognition 167:25-37

Bear A and Knobe J (2017b) The normalization trap. The New York Times. 28 January. https://www.nytimes.com/2017/01/28/opinion/sunday/thenormalization-trap.html. Accessed 16 Oct 2018

Bicchieri C (2017) Norms in the wild: how to diagnose, measure, and change social norms. Oxford University Press, New York

Bicchieri C, Mercier H (2014) Norms and beliefs: how change occurs. Iyyun Jerus Philos Q 63:60-82

Bilz K, Nadler J (2014) Law, moral attitudes, and behavioral change. In: Zamir E and Teichman D (eds) The Oxford handbook of behavioral economics and the law. Oxford University Press, New York, pp. 241-267

Bollard L (2017) How can we achieve breakthrough change for farm animals? Open Philanthropy Farm Animal Welfare Newsletter, 22 February. https://us14. campaign-archive.com/?

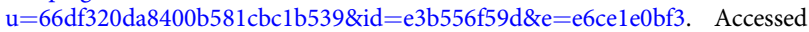
16 Oct 2018

Budolfson M (2015a) Is it wrong to eat meat from factory farms? If so, why? In: Bramble B and Fischer B (eds) The moral complexities of eating meat. Oxford University Press, New York

Budolfson M (2015b) Consumer ethics, harm footprints, and the empirical dimensions of food choices. In: Chignell A, Cuneo T, Halteman CM (eds) Philosophy comes to dinner. Routledge, New York

Caviola L, Everett JAC, Faber NS (2018) The moral standing of animals: towards a psychology of speciesism. J Personal Soc Psychol. https://doi.org/10.1037/ pspp0000182

Cummins AN, Widmar O, Croney C and Fulton J (2015) Perceptions of United States residents: animal agriculture and meat products. Center for Animal Welfare Science, Purdue University, West Lafayette. https://www.vet.purdue. edu/CAWS/files/documents/062215-WhitePaperNATIONAL.pdf. Accessed 16 Oct 2018

Graham J, Haidt J, Nosek BA (2009) Liberals and conservatives rely on different sets of moral foundations. J Pers Soc Psychol 96:1029-1046

Graham J, Nosek BA, Haidt J, Iyer R, Koleva S, Ditto PH (2011) Mapping the moral domain. J Pers Soc Psychol 101:366-385

Haidt J, Graham J (2007) When morality opposes justice: conservatives have moral intuitions that liberals maynot recognize. Soc Justice Res 20:98-116

Jacquet J (2015) Is shame necessary? New uses for an old tool. Pantheon Books, New York

Joy M (2009) Why we love dogs, eat pigs, and wear cows. Conari Press, San Francisco 
Kasperbauer TJ (2018) Subhuman: the moral psychology of human attitudes to animals. Oxford University Press, New York

Kuenzler A, Kysar DA (2014) Environmental law. In: Zamir E, Teichman D (eds) The Oxford hand book of behavioral economics and the law. Oxford University Press, New York, pp 748-782

Leiter B (2013) The boundaries of the moral (and legal) community. Ala Law Rev 64:511-531

McAdams RH (2000a) Attitudinal theory of expressive law. Oregon Law Rev 79:339-390

McAdams RH (2000b) Focal point theory of expressive law. Va Law Rev $86: 1649-1729$

McAdams RH (2015) The expressive powers of law: theories and limits. Harvard University Press, Cambridge, MA

Nefsky J (2018) Consumer choice and collective impact. In: Barnhill A, Budolfson M, Doggett T (eds) The Oxford handbook of food ethics. Oxford University Press, New York

Nichols S (2004) Sentimental rules: on the natural foundations of moral judgment. Oxford University Press, New York

Nussbaum MC (2004) Hiding from humanity: disgust, shame, and the law. Princeton University Press, Princeton

Pettit P (2002) Rules, reasons, and norms. Oxford University Press, New York Piazza J, Matthew BR, Loughnan S, Luong M, Kulik J, Watkins HM, Seigerman M (2015) Rationalizing meat consumption. The 4Ns. Appetite 91:114-128

Posner EA, Sunstein CR (2017) Moral commitments in cost-benefit analysis. Va Law Rev 103:1809-1860

Prentice DA, Miller DT (1996) Pluralistic ignorance and the perpetuation of social norms by unwitting actors. In: Zanna MP (Ed.) Advances in experimental social psychology (Vol. 28). Academic Press, San Diego, p 161-209

Rosenberg G (2008 [1991]) The hollow hope: can courts bring about social change? 2nd edn. The University of Chicago Press, Chicago

Shapiro P (2018) Clean meat: how growing meat without animals will revolutionize dinner and the world. Gallery Books, New York

Sunstein CR (1996) Social norms and social roles. Columbia Law Rev 96:903-968

Wolfson DJ, Sullivan M (2004) Foxes in the henhouse: Animals, agribusiness, and the law: a modern Americanfable. In: Sunstein CR, Nussbaum MC (eds) Animal rights: current debates and new directions.OxfordUniversity Press, New York, pp 205-206

\section{Acknowledgements}

Thanks to my colleagues at the University of Chicago Law School during the 2017-2018 academic year, especially Todd Henderson, Brian Leiter, Saul Levmore, and Martha Nussbaum, among many others. Ideas developed here have also benefitted from conversations with Mark Budolfson, Bob Fischer, Jeff Johnson, and TJ Kasperbauer at the 2018 meeting of the Pacific Division of the American Philosophical Association.

\section{Additional information}

Competing interests: The author declares no competing interests.

Reprints and permission information is available online at http://www.nature.com/ reprints

Publisher's note: Springer Nature remains neutral with regard to jurisdictional claims in published maps and institutional affiliations.

(c) (i) Open Access This article is licensed under a Creative Commons Attribution 4.0 International License, which permits use, sharing, adaptation, distribution and reproduction in any medium or format, as long as you give appropriate credit to the original author(s) and the source, provide a link to the Creative Commons license, and indicate if changes were made. The images or other third party material in this article are included in the article's Creative Commons license, unless indicated otherwise in a credit line to the material. If material is not included in the article's Creative Commons license and your intended use is not permitted by statutory regulation or exceeds the permitted use, you will need to obtain permission directly from the copyright holder. To view a copy of this license, visit http://creativecommons.org/ licenses/by/4.0/.

(c) The Author(s) 2018 